\title{
Teacher Professional Development: Field of Knowledge Rise
}

\author{
Raissa Silveira De Farias, Adriana Maria Procopio De Araujo \\ School of Economics, Business Administration and Accounting at Ribeirao Preto Accounting Department, University of Sao \\ Paulo, Sao Paulo, Brazil \\ Email: farias.issa@usp.br, amprocop@usp.br
}

How to cite this paper: De Farias, R. S., \& De Araujo, A. M. P. (2018). Teacher Professional Development: Field of Knowledge Rise. Creative Education, 9, 658-674. https://doi.org/10.4236/ce.2018.95048

Received: February 23, 2018

Accepted: April 17, 2018

Published: April 20, 2018

Copyright (c) 2018 by authors and Scientific Research Publishing Inc. This work is licensed under the Creative Commons Attribution International License (CC BY 4.0).

http://creativecommons.org/licenses/by/4.0/

\begin{abstract}
The research aims to analyze the international scientific production in the field of "teacher professional development". We used the Web of Science database, in which 811 articles-published from 1987 to 2017, and $62.64 \%$ of them published in the last five years-were mapped. On this basis, it is confirmed that the field of knowledge at issue is recent, and it has been explored in the last years. The publications reviewed involved 1918 authors, from 67 countries and 295 different journals. Among the most expressive countries, the United States and Australia stood out, with $49 \%$ of the publications on this theme. The journal with the greatest number of publications was Teaching and Teacher Education, containing 66 articles published in the period. Analyzing the authorship, the one-timer's category stood out, with $88 \%$ of the publications. The largest production was of 11 papers by author and the most mentioned one had 157 citations. It was concluded that the thematic has been getting attention from the researchers of several fields of knowledge, including business, and that the authors inserted in the theme are seeking the consolidation of the theoretical basis regarding the subject by using empirical work.
\end{abstract}

\section{Keywords}

Teacher, Professional Development, Education

\section{Introduction}

The study of the teacher professional development aims the quality of teaching and the training of future professional, since the understanding of this process helps the improvement of teacher training and, the consequent improvement of their teaching practices.

In the report published by the Organisation for Economic Co-operation and 
Development (OECD), it is stated that a substantial number of studies explains the quality of teacher training and the way they teach is the most important factor to explain how much the students learn. "There is now substantial research indicating that the quality of teachers and their teaching are the most important factors in student outcomes that are open to policy influence" (OECD, 2005: p. 9).

The teacher qualification is consolidated, from several learning experiences (Miccoli, 1997), and the set of these experiences and systematic analysis of their own practice leads to their professional development (Villegas Reimers, 2003).

Nevertheless, a process will have its results optimized from the understanding of itself. Thus, in order to make the teacher professional development easy, the process by which the teachers grow professionally and the conditions which support and promote such growth have to be understood (Clarke \& Hollingsworth, 2002). A way to understand the teacher professional development is from his/her own learning experiences (Day, 1999; Villegas Reimers, 2003).

The studies developed focusing on the teacher professional development (Andersson \& Palm, 2017; Clarke \& Hollingsworth, 2002; Desimone, 2009; Marcelo, 2009) seek, by means of specific studies-theoretical and empirical, the effectiveness of teacher professional development and the consequent improvement in the students' performance, approaching the teaching and learning process.

This study proposal is to understand the theme, by the analysis of the international scientific production, and the future trends on the theme. In order to do so, it proposes to answer the following research question: how has the scientific production on "teacher professional development" been framed lately?

To reach this purpose, a bibliographic research was carried out, based on the application of bibliometric procedures, aiming to promote an analysis of the field of knowledge on teacher professional development. The sample comprised 811 articles, published from 1987 to 2017. The data analysis was held in three stages, and it took place from the ranking of the articles in categories, from the HistCite software, an analytical tool which allows to identify the most significant work within a scientific field and track its evolution, besides identifying highly productive and highly mentioned authors in any research field chosen, as well as the most mentioned papers (Thulasi \& Arunchalam, 2010).

The study provides the field researchers, whose study object is teachers and their qualification, an overview of what is researched in the field, and the course coordinators who worry about the quality of the faculty, as well as those who develop programs of teacher training programs aiming to develop, improve and qualify high education teachers to develop themselves profissionally.

The discussion which permeated the definition of professional development, and more specifically, the teacher professional development, has been built and designed by some authors in the education field, such as Day (1999); Hargreaves \& Fullan (1992); Kelchtermans (1995); Villegas Reimers (2003); Marcelo (2009). 
In this study, it was chosen to use the approach referring to professional development, and not, teacher training, following the logic carried out by Marcelo (2009), who justifies the designation "professional development" as the most suitable one to the concept of teacher as teaching professional, since the concept "development" has the connotation of evolution and continuity that, for the author, overcomes the traditional juxtaposition between the teachers' initial training and ongoing training.

Associated with this justification, the teaching complexity is added, which requires "teachers to commit themselves to a process of career-long professional development" (Day, 2001: p. 16), through the experiences of learning experienced by the teachers, which have as objective "to contribute to the improvement of the quality of education in classrooms" (p. 4).

Complacent to this view, Rudduck (1991: p. 129) refers to the teacher professional development as "the teacher's ability to maintain the interest in his group; identify significant interests in the teaching and learning process; value and seek debate with senior colleagues as support in the analysis of situations". Thus, the teacher professional development (TPD) can be understood as a constant and evolving attitude of thinking and action, through the result of his experience and the systematic analysis of his own practice (Villegas Reimers, 2003).

Furthermore, in order to the professional development to take place, Heideman (1990) warns that the teachers must be open to change. The professional development, according the author, will happen if the purpose is to modify the teaching-learning activities, change the teachers' attittudes and improve the students' school outcomes. The teacher needs to have interrelationship of the concerns which go way beyond the individual, professional and organizational needs around him/her.

Day (1999) broadened this view when encompassing in the professional development all the natural learning experiences, which reflected, can be incorporated to the improvement of the educational quality in the classroom. For the author, professional development is seen as a process by which,

It is the process by which, alone and with others, teachers review, renew and extend their commitment as change agents to the moral purposes of teaching; and by which they acquire and develop critically the knowledge, skills and emotional intelligence essential to good professional thinking, planning and practice with children, young people and colleagues through each phase of their teaching lives (Day, 1999: p. 4).

Another approach regarding teacher professional development is given by Kelchtermans (1995), from five perspectives centered in changes that occurred during the career path and through an autobiographical approach. The five perspectives are called narrative, constructivist, contextualized, interactionist and dynamics. The author conceptualize, from these perspectives, the professional development in the meaning and in the constructive process that the experiences and consequent accounts have for the teachers, as well as his speeches 
about the context where they intervene, significant interactions with these contexts and the dynamics between thought and action in certain moments of professional development.

Thus, professional teacher development can be understood as a long-term process, which develops throughout the professional career of the teacher, and "integrates different types of opportunities and experiences, systematically planned, in order to promote growth and development professional teachers" (Villegas Reimers, 2003: p. 12).

Due to the complexity of the process of development and professional growth and to the difficulty in understanding the factors which affect such development, over the past decades, teacher professional development models were developed, and steadily improved in order to meet the demands identified in the improvement of the teaching practices, by authors, such as: Clarke \& Hollingsworth (2002); Guskey \& Sparks (2002); Marcelo (2009), who are the most mentioned ones in the literature consulted.

Researchers as Fullan (1982) recognized that many programs of teaching training do not consider the teacher professional change process. Such programs usually tried to change the teachers' beliefs and attitudes, expecting that changes in these points would lead to changes in practices and behaviors in the classroom.

Nevertheless, Marcelo (2009) identified that this logic implicit in the programs of teacher training do not reflect the reality of the teacher professional development process, and it is its main criticism. According to the author, the implicit purpose of many programs of ongoing teacher training is the changes in teachers' knowledge and beliefs, who, in turn provoke a change in teaching practices in the classroom and, consequently, a probable improvement in the students' learning outcomes. The prerrogative is that teacher training, causes changes in the knowledge and beliefs and these are conditioned in the behavior of the classes (students) topping up with the change in the students' learning outcomes.

When discussing these programs, Guskey \& Sparks (2002) pointed gaps in the change view of the implicit logic model and supplied an alternative model. The authors state that significant changes in beliefs and attitudes took place, but not as consequence of his participation in activities of professional development, but proving, in practice, the use and feasibility of these new practices which they want to develop and, its consequence on the students' learning outcome.

Another model of teacher change process was developed by Clarke \& Peter (1993), and later reviewed by an international research group interested in the teacher professional growth, such as the Interconnected Model of Teacher Professional Growth. This model was, in a second moment, outlined by Clarke \& Hollingsworth (2002), and it comes up from the criticism to previous models, since they did not reflect the complexity of the teachers' learning processes. Thus, the authors propose not a linear model, but an interrelated one. 
The Inter relational Model of Professional Development, developed by Clarke \& Hollingsworth (2002), suggests that the development of the changes occurs through two mediating processes of "thinking" and "application", in four distinct domains: personal domain (his knowledge, beliefs and attitudes), the domain of teaching practice (work experience), domain of consequence in the students' learning (prominent outcomes) and external domain (information, stimuli or support sources).

Clarke \& Hollingsworth (2002) defend that the professional development is produced both by the teachers' thinking, and the implementation of new procedures; these mediating processes are represented, in the model, as arrows linking the domains. This model recognizes the complexity of professional development by the identification of multiple development path between the domains.

Its non-linear nature and the fact of recognizing the professional development as an unavoidable and ongoing learning process, distinguishes this model from others identified in the research literature. This model also identifies the mediating processes of thinking and implementation as the mechanisms by which the change in a domain leads to change in another one. Any professional growth process represented in the model takes place within the limitations and possibilities of the overwhelming change environment (Hollingsworth, 1999).

The implementation mediating process is considered the mechanism in which a new idea or a new belief or a new recently discovered practice is put into action. The thinking mediating process occurs when the teacher tries new practices in the classroom and, then, thinks over and interprets the events occurred in terms of the results found and concludes on the consequent changes on these salient outcomes, in the students' learning. The nature of the inferences taken fully depends on the teacher's value system.

The field of knowledge on teacher professional development has been studied, improved and presented in the literature in many different ways. Nevertheless, the key aspect which rules such studies focuses on the understanding that professional development is a complex process, by which the teachers grow profissionally through their learning experiences (Clarke \& Hollingsworth, 2002; Day, 1999; Villegas Reimers, 2003), aiming to change their knowledge into practice for the benefit of their students' growth.

In this sense, Marcelo (2009: p. 10) discusses a new perspective regarding professional teacher development, which has the following characteristics:

1) it is based on constructivism, not on the transmissive models, understanding that the teacher is a subject who actively learns to be involved in concrete tasks of teaching, evaluation, observation and reflection; 2) it is understood as a long-term process, which recognizes that teachers learn over time. Thus, experiences are considered to be most effective if teachers are allowed to relate the new experiences to their previous knowledge. For this, it is necessary that an appropriate follow-up is, so that the change can take place; 3 ) it is assumed as a process that takes place in concrete contexts. The reverse of traditional 
practices that don't relate training situations to classroom practices, the most effective experiences for teacher professional development are those that are school-based and relate to daily activities performed by teachers; 4) professional teacher development is directly related to the processes of school reform, insofar as it is understood as a process that tends to rebuild the school culture and in which teachers are implicated as professionals; 5) the teacher is seen as a reflexive practitioner, someone who has prior knowledge when entering the profession and who is acquiring more knowledge from a reflection about his experience. Thus, professional development activities consist of helping teachers build new theories and new pedagogical practices; 6) professional development is conceived as a collaborative process, although it is assumed that there may be space for isolated work and reflection; 7) professional development can take different forms in different contexts. For this reason, there is no one and only one model of professional development that is effective and applicable in all schools. Schools and teachers should evaluate their own cultural needs, beliefs and practices to decide which model of professional development is most beneficial to them.

There is, therefore, a constant need of studying, trying, discussing and reflecting on teacher professional development about the links and influence of history and traditions of teacher groups, the educational needs of student populations, the teachers' working conditions and the learning opportunities which are open to them (Avalos, 2011).

In the last thirty years, since the first record of the term "teacher professional development", a large number of articles have been published and are aimed at teachers, their teaching trainers and educational managers, aimed at the professional development and its impact on the teaching quality and on the students' learning.

\section{Methodology and Methods}

The methodology adopted in this study is based on the bibliographic research and in the application of bibliometric procedures, aiming to promote na analysis of the field of knowledge on teacher professional development. As stated by Guedes \& Borschiver (2005), the scientific productions regarding a field of knowledge, and generate different indicators of treatment and information and knowledge management, and of productivity, necessary for the planning, assessment and science management in a certain scientific community.

For the definition of the study sample, the Web of Knowledge tool, Web of Science database, for the publication period from 1987 to 2007, since the beginning of publications in this field of knowledge. For the bibliometric analysis, the Hist Cite software was used; it is an analytical tool which allows to identify the most significant work within a scientific area and track its evolution, besides identifying highly productive and highly mentioned authors, as well as the most cited papers in any research field chosen, (Thulasi \& Arunachalam, 2010). 


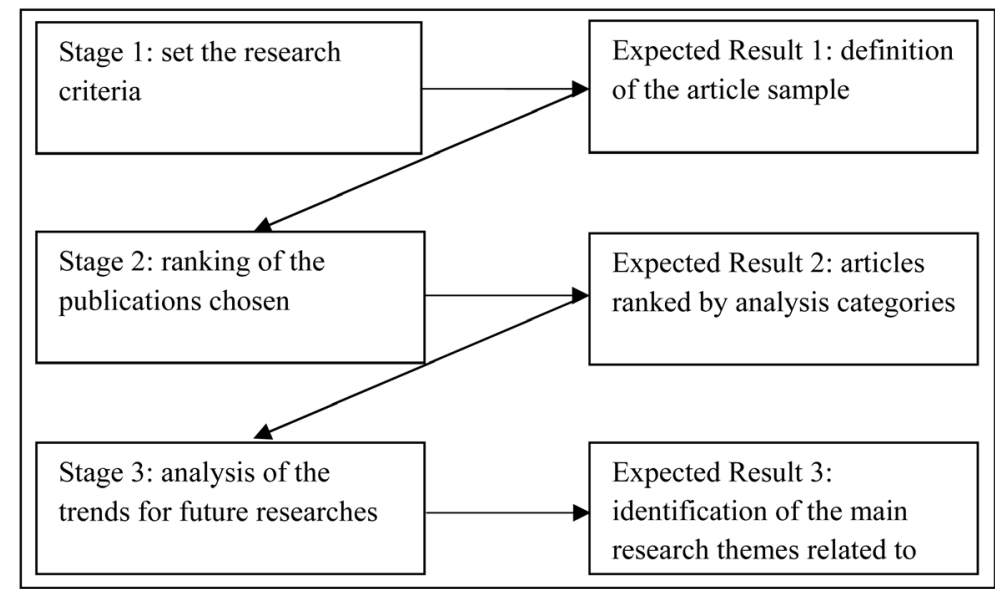

Chart 1. Representation of the research development stages. Source: adapted from Silva, Silva, \& Ometto (2016).

For the development of the study, three stages were carried out (Silva, Silva \& Ometto, 2016), as shown in Chart 1. In the first stage, the research criteria was set and the search for the key word in the Web of Knowledge took place. Thus, at first, the publications were chosen according the criteria: type of document-article and type of publication-academic journal. The term used as key word was the expression. "teacher professional development", used in the title and topic search criteria. Altogether, 1138 articles were found and 811 of them were chosen for analysis.

In the second stage, the ranking of the publications chosen was performed and the analysis category were: publication date, country of origin, institutions involved and name of the journal. For the work authorship, the authors were classified according to the productivity in the field (number of articles published and number of citations received) and the productive framework (continuants, transients, newcomers, one-timers and terminators) (Walter \& Bach, 2013). For the analysis of citation number, the bibliometric indicators of the Hist Cite software were used.

Finally, the third stage was developed from the analysis of the results, by which future trends for researches in the field of knowledge in teacher professional development were identified. In order to do so, the crossing of the themes of the main articles published together with the themes of the most recent articles published was made (Chart 1).

\section{Results and Discussion}

\subsection{Evolving Analysis, Country of Origin, Institutions Involved}

The search for articles published on "teacher professional development", in October/2017, resulted in 1,138 results, of which 811 were used in this study according to the "article" refining criterion, from 1987 to 2017, totaling 30 years of publications in this field.

Since the beginning of the publications on the theme, in 1987, the period 
which stands out is the last five years (2013-2017), which means $62.64 \%$ of the articles were published in this period, indicating the rise of the theme in recent years, with special focus on 2016, which had the largest number of publications, totaling 166 articles as shown in Picture 1.

Opfer \& Pedder (2011) state that in the late 1980's and beginning of the 1990's, many authors discussed the teaching and learning as situational, contextual or ecological. Nevertheless, the boost in educational research for the scientification in the late 1990's and 2000 became more mechanistic and linear due to causal studies and the growth of the linear statistical modeling (Lather, 2005). As a result, the conceptual growth in the complex understanding carried out in the previous period came to a standstill, and more recently, it reappeared with the work of theorists regarding the subject.

Regarding the country of origin of the publications, 67 countries were identified, with focus on the United States and Australia with 403 articles published, concentrating $49.7 \%$ of the publications on the theme. Chart 2 shows the characterization of the article sample according to the country of origin.

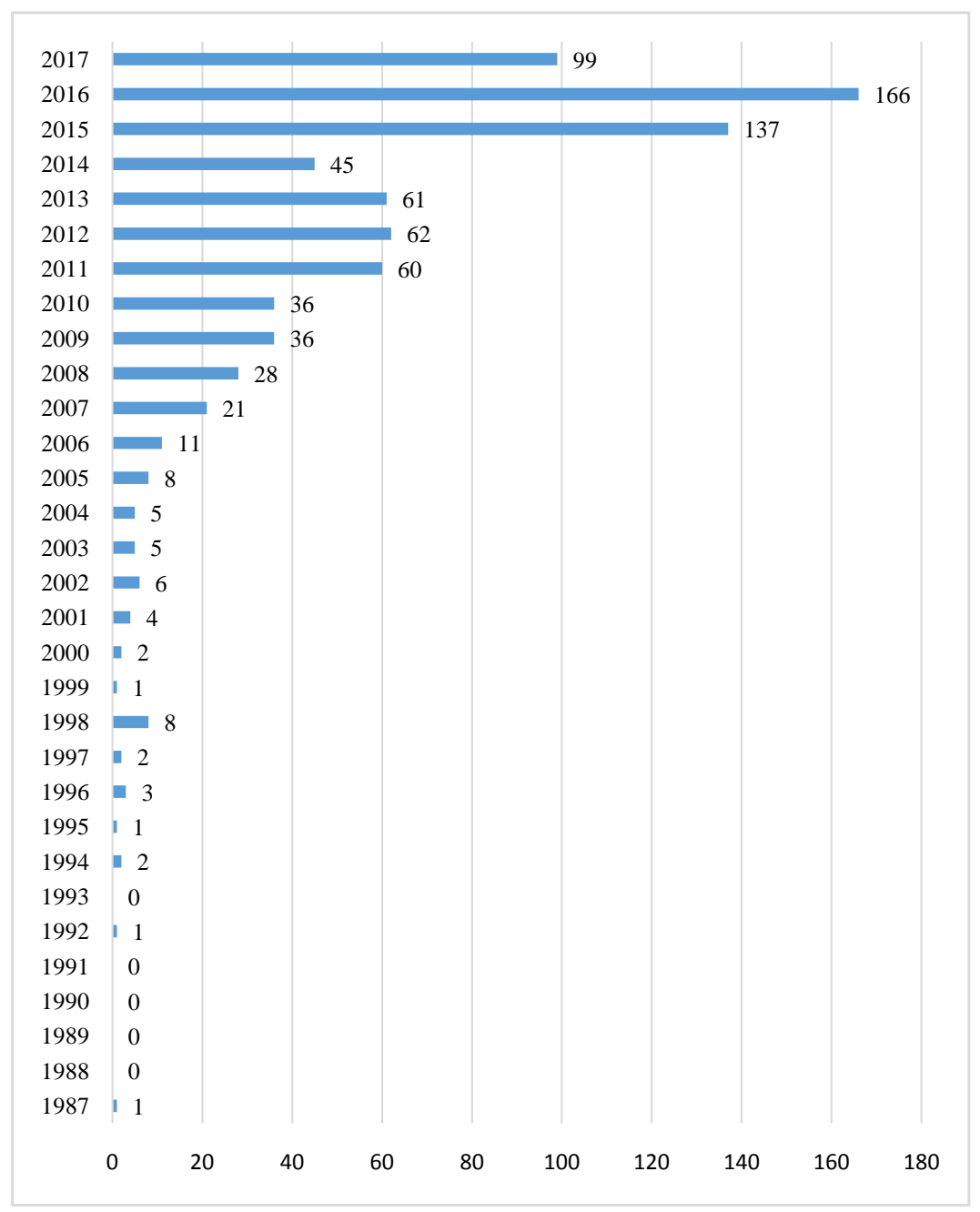

Picture 1. Number of publications per year. Source: research data. 
Chart 2. Number of publications per country of origin.

\begin{tabular}{ccc}
\hline Country & Number of publications & $\%$ \\
\hline The United States & 295 & $36 \%$ \\
Australia & 108 & $13 \%$ \\
The United Kingdom & 62 & $8 \%$ \\
The Republic of China & 55 & $7 \%$ \\
The Netherlands & 36 & $4 \%$ \\
Canada & 34 & $4 \%$ \\
South Africa & 31 & $4 \%$ \\
Singapora & 28 & $3 \%$ \\
Spain & 24 & $3 \%$ \\
New Zealand & 23 & $3 \%$ \\
Taiwan & 21 & $3 \%$ \\
Israel & 14 & $2 \%$ \\
Germany & 13 & $2 \%$ \\
Ireland & 12 & $1 \%$ \\
Sweden & 11 & $1 \%$ \\
Others & 44 & $5 \%$ \\
\hline
\end{tabular}

Source: research data.

The publications center on the following countries: the United States, Australia, the United Kingdom, the Republic of China, the Netherlands, Canada, South Africa, Singapore, Spain, New Zealand, Taiwan, Israel, Germany, Ireland and Sweden. Other 44 articles are distributed in countries which published 1 to 10 articles each. Moreover, it is highlighted that Brazil contributed with 5 articles in this sample, characterizing its low representativity in the field, and opportunity for new researches.

Regarding the institutional affiliation of the publications analyzed, 685 institutions were identified, 507 of them were universities, which corresponds to $74 \%$ of the sample analyzed. Other institutions found are related, for the most part, to research institutions and non-profit organizations.

Among the universities, the ones which stood out were: Nanyang Technological University (Singapora), Hong Kong Institute of Education (Hong Kong) and the University of Queensland (Australia), characterized by the institutions involved in the publications of the articles which were the object of this analysis (Chart 3).

The Brazilian institutions involved in articles published on teacher professional development were: Federal University of Rio de Janeiro, State University of Bahia, Federal University of Mato Grosso do Sul, State University of Rio de Janeiro and Federal University of Paraná. Thus, the "teacher professional development" theme has arisen, at a global level, more interest in Universities in the 
Chart 3. Number of publications per country of origin.

\begin{tabular}{cccc}
\hline University & Country & Number of publications & $\%$ \\
\hline Nanyang Technological University & Singapora & 27 & $3.3 \%$ \\
Hong Kong Institute of Education & Hong Kong & 20 & $2.5 \%$ \\
University of Queensland & Australia & 16 & $2.0 \%$ \\
University of Cambridge & England & 15 & $1.8 \%$ \\
Purdue University & United States & 14 & $1.7 \%$ \\
University of Hong Kong & Hong Kong & 14 & $1.7 \%$ \\
Michigan State University & United States & 12 & $1.5 \%$ \\
New York University & United States & 12 & $1.5 \%$ \\
University of Virginia & United States & 12 & $1.5 \%$ \\
Newcastle University & United Kingdom & 11 & $1.4 \%$ \\
Harvard University & United States & 10 & $1.2 \%$ \\
Open University & United Kingdom & 10 & $1.2 \%$ \\
Penn State University & United States & 10 & $1.2 \%$ \\
University of KwaZulu-Natal & South Africa & 10 & $1.2 \%$ \\
\hline
\end{tabular}

Source: research data.

United States, the United Kingdom and Hong Kong.

\subsection{Analysis of the Publications in Journals Involved}

Regarding the journals which published on the field of knowldege related to the teacher professional development, the ones in Chart 3 seem to be the most influenced ones in the area. Altogether, 295 journals were identified, and the one which stands out, having the largest number of publications, is the Teaching and Teacher Education jornal, in which 66 articles were published during the period analyzed. The most influential ones accounted for $60.67 \%$ of the total of the publications, and each one of them had from 10 to 66 articles published, according to the information shown on Chart 4.

The Teaching and Teacher Education Journal presents an impact factor of 2.183 in the last year and 2.995 in the 5-year accumulated. The International Journal of Science Education also presents an impact factor above 1.

Picture 2 presents the publication rolling on teacher professional development for the main journals identified from 2006 to 2017 . The choice for this period is justified by the fact that the publication of the journals chosen started in 1992, and until 2005, the frequency of publications on this field was low, between 0 and 1 articles, except in 1998, when 4 articles were published.

Thus, it is observed that most of the journals do not have linearity when publishing on theme. Such a fact may be due to the multidisciplinarity of the journal. The Teaching and Teacher Education journal, for instance, is aimed at not being committed to any approach, subject, methodology or single paradigm, that 


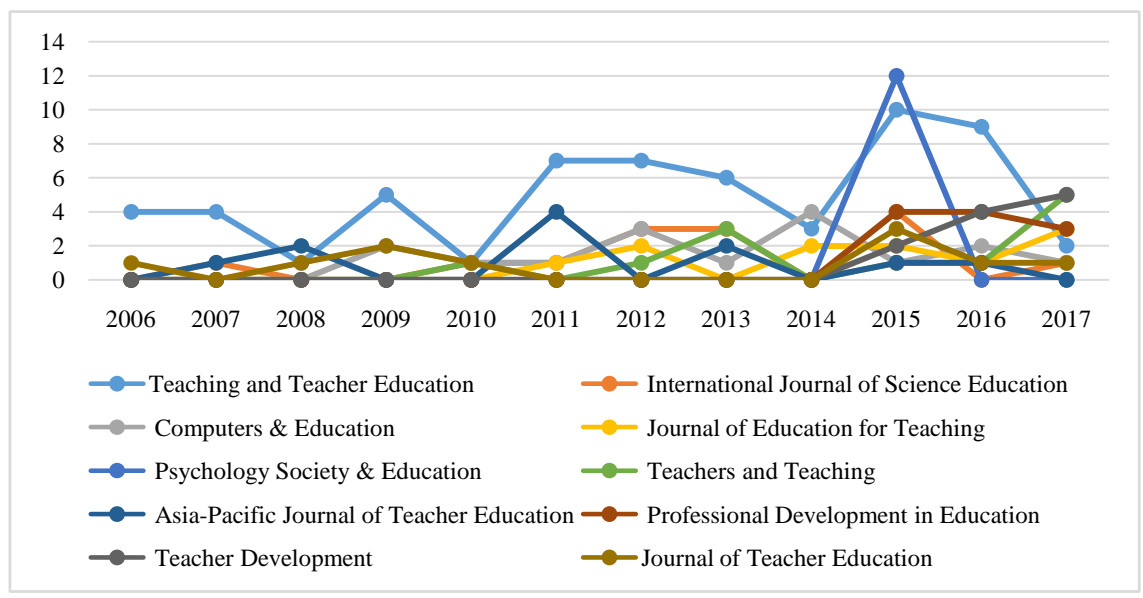

Picture 2. Journal trend. Source: research data.

Chart 4. Number of publications per journal.

\begin{tabular}{ccc}
\hline Name & Number of publications & $\%$ \\
\hline Teaching and Teacher Education & 66 & $22 \%$ \\
International Journal of Science Education & 18 & $6 \%$ \\
Computers \& Education & 16 & $5 \%$ \\
Journal of Education for Teaching & 12 & $4 \%$ \\
Psychology Society \& Education & 12 & $4 \%$ \\
Teachers and Teaching & 12 & $4 \%$ \\
Asia-Pacific Journal of Teacher Education & 11 & $4 \%$ \\
Professional Development in Education & 11 & $4 \%$ \\
Teacher Development & 11 & $4 \%$ \\
Journal of Teacher Education & 10 & $3 \%$ \\
Others & 116 & $39 \%$ \\
\hline
\end{tabular}

Source: research data.

is, it is open to articles which are related to teaching and teacher training in general.

\subsection{Analysis of Publication Authorship}

Regarding the productive framework, Chart 5 presents the number of authors identified per authorship category. This analysis resulted in classifying the authors in the categories adapted from Guarido Filho, Silva, \& Gonçalves (2009): 1) newcomers: new researchers in the field (who published from 1 to 2 articles just in the last three years); 2) transients: researchers who are relatively permanent in the field (who published, at least, two articles in up to 4 different years, either in the last 3 years or before that); 3) continuants: researchers consolidated in the field (who published, at least two articles in five or more different years, including the last 3 years); 4) one-timers: sporadic researchers (who published 
Chart 5. Productive framework of the authors in the field.

\begin{tabular}{ccc}
\hline Categories & Number of authors & $\%$ \\
\hline Newcomer authors & 142 & $7.4 \%$ \\
Continuant authors & 6 & $0.3 \%$ \\
Transient authors & 0 & $0 \%$ \\
One-timer Authors & 1,689 & $88.0 \%$ \\
Terminator Authors & 81 & $4.3 \%$ \\
Total & 1,918 & $100 \%$ \\
\hline
\end{tabular}

Source: Research data.

just one article in the whole period); and terminators: researchers who are leaving the field (who published, at least 2 articles, but none in the last 3 years).

In all, 1918 different authors were identified, as seen in Chart 5. The newcomers, continuants, transients and terminators present little or none expressiveness in the publications mapped, different from the one-timer category, which stood out the most, representing $88 \%$ of the publications. Such findings include the fact that the "teacher professional development" theme was recently added to the scientific production of the international academy.

Regarding the productivity of the authors in the field, in Chart 6, the ranking of the main authors according to the number of articles published is presented.

It is observed that two of the main authors, 7 out of the 1918 authors mapped, are from the United States and two from Australia, the two countries which stand out the most in publications in the field. The maximum number of articles published per author varied from 5 to 11 . Therefore, it is observed that most of the publications (99.6\%) is broken up among the 1911 authors, who published 1 to 4 articles each, a fact which can be attributed to the large number of institutions involved in researches on the theme.

Corroborating the above information, there is also the fact that the most part of the authors mapped had been classified as one-timer researchers, sporadic and unconsolidated researchers in the field. Regarding the 7 main authors in Chart 6, two are classified as newcomers, two as transients, two as constinuants and one as terminator.

Considering that an author's productivity must also take into account the number of citations his publications had, Chart 7 ranks the authors mapped according to the number of Global Citation Score (GCS) citation type.

Out of the 28,859 GCS citations, in Chart 7, it is observed that 12 authors are the main ones, whose citation numbers vary from 35 to 157 . Nine (9) out of the total are from the United States, one is from Russia, 1 is from Chile and 1 of them does not have any affiliation, at the moment; altogether they represent $3 \%$ of the citations. Thus, it is observed that most part of the citations is broken up (97\% of the 1,918 authors mapped).

When analysing the productivity of the main TPD authors, different findings 
Chart 6. Main authors in the field.

\begin{tabular}{cccc}
\hline Author & Country & Number of articles published & $\%$ \\
\hline Ian Hardy & Australia & 11 & $0.57 \%$ \\
Okhee Lee & the United States & 7 & $0.36 \%$ \\
Alfredo Bautista & Singapora & 5 & $0.26 \%$ \\
Ching Sing Chai & Singapora & 5 & $0.26 \%$ \\
David Lubans & Australia & 5 & $0.26 \%$ \\
Luanna Meyer & New Zealand & 5 & $0.26 \%$ \\
Robert Pianta & the United States & 5 & $0.26 \%$ \\
Outros & Several & 1911 & $99.6 \%$ \\
\hline
\end{tabular}

Source: research data.

Chart 7. Number of citations of the main authors in the field.

\begin{tabular}{cccc}
\hline Author & Country & Number of GCS citations received & $\%$ \\
\hline Hilda Borko & the USA & 157 & 0.54 \\
Lee Shulman & the USA & 121 & 0.41 \\
Michael S. Garet & the USA & 115 & 0.40 \\
Laura M. Desimone & the USA & 112 & 0.39 \\
Thomas R. Guskey & the USA & 77 & 0.27 \\
Donald Schon & the USA & 48 & 0.17 \\
Étienne Wenger & no affiliation & 45 & 0.16 \\
Lev Vygotsky & Russia & 43 & 0.15 \\
Jean Lave & the USA & 42 & 0.14 \\
Beatrice Avalos & Chile & 38 & 0.13 \\
David Clarke & the USA & 35 & 0.12 \\
Suzanne M. Wilson & the USA & 35 & 0.12 \\
Others & & 27,991 & 97 \\
\hline
\end{tabular}

Source: research data

are observed, according to the comparison criteria. From the Chart 6 and Chart 7 , it is observed that the authors with the largest number of publications are not the ones who had the largest number of citations. In Chart 5, more than $90 \%$ of the authors were classified as one-timers or terminators, and the majority of their articles date from 1997-2005; moreover, 6 authors were classified as continuants. Differently, in Chart 6, two of the outstanding authors were classified as continuants, and the other five were considered transients, that is researchers who are relatively constant in the field.

Thus, it can be inferred that the authors in Chart 6 are the main researchers in the field nowadays. On the other hand, the authors in Chart 7 are, mostly, leaving the field (terminators) or are not great "actors" (one-timers); neverthe- 
less, their works, although retrospective, serve as basis for the continuity and development of more TPD publications.

\subsection{Analysis of Future trends}

In this section, the future trends for researches on Teacher Professional Development are identified. First, the main themes studied in the field were mapped chosing the articles with the highest LCS (Local Citations Scale) values, as shown in Picture 3 and in Chart 8.

Out of the main authors (Chart 7), two of them stand out in Chart 8, Laura Desimone and Beatrice Avalos. All the works date from 2002-2011 and, most of them, involve authors classified as terminators.

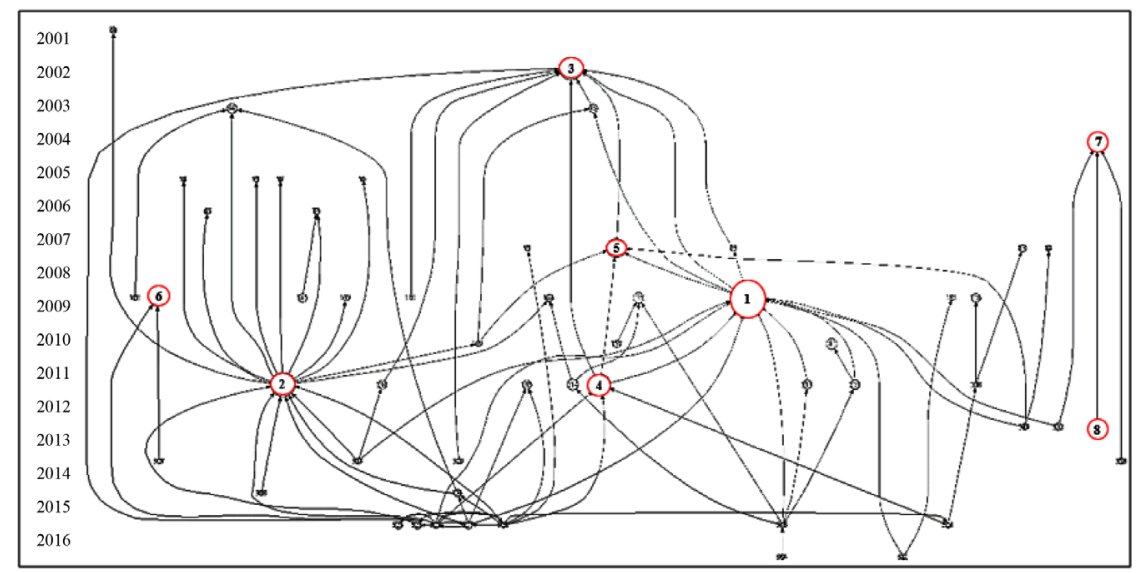

Picture 3. Map of the relationship between the publications analyzed. Source: Research data.

Chart 8. Main publications mapped.

\begin{tabular}{|c|c|c|c|c|c|}
\hline & Authorship & Year & Theme Studied & Study Type & LCS \\
\hline (1) & Desimone, L.M. & 2009 & $\begin{array}{l}\text { Improving impact studies of teachers' } \\
\text { professional development: toward better } \\
\text { conceptualizations and measures }\end{array}$ & Theoretical & 78 \\
\hline (2) & Avalos, B. & 2011 & $\begin{array}{l}\text { Teacher professional development in teaching } \\
\text { and teacher education over ten years }\end{array}$ & Theoretical & 38 \\
\hline (3) & $\begin{array}{l}\text { Desimone, L.M., } \\
\text { et al. }\end{array}$ & 2002 & $\begin{array}{l}\text { Effects of professional development on teachers' } \\
\text { instruction: results from a three-year longitu- } \\
\text { dinal study }\end{array}$ & Empirical & 34 \\
\hline (4) & $\begin{array}{l}\text { Opfer, V.D., } \\
\text { Pedder, D. }\end{array}$ & 2011 & $\begin{array}{c}\text { Conceptualizing teacher professional } \\
\text { learning }\end{array}$ & Theoretical & 28 \\
\hline (5) & Wayne, A.J., et al. & 2008 & $\begin{array}{l}\text { Experimenting with teacher professional } \\
\text { development: motives and methods }\end{array}$ & Theoretical & 24 \\
\hline (6) & Dede, C., et al. & 2009 & $\begin{array}{c}\text { A research agenda for online teacher } \\
\text { professional development }\end{array}$ & Theoretical & 19 \\
\hline (7) & Ertmer, P. A. & 2005 & $\begin{array}{l}\text { Teacher pedagogical beliefs: the final } \\
\text { frontier in our quest for technology integration? }\end{array}$ & Theoretical & 15 \\
\hline (8) & Ertmer, P.A., et al. & 2012 & $\begin{array}{l}\text { Teacher beliefs and technology integration } \\
\text { practices: a critical relationship }\end{array}$ & Empirical & 12 \\
\hline
\end{tabular}

Source: research data. 
From the analysis of the main publications mapped, most cited articles regarding teacher professional development, it is observed that the majority are theoretical articles, which corroborates with the rise of the field in the last five years, and the recent recovery (since 2006) of the researches regarding the subject in question, and by means of some empirical works which consolidate them.

\section{Conclusion}

The study aimed to carry out an analysis of the international scientific production in the teacher professional development research field. In order to do so, the Web of Science database was used, by which 811 articles, published from 1987 to 2017, were mapped, totaling 30 years of publications in the field, including 1918 authors, from 67 countries and 295 different journals.

The articles of the sample were analyzed based on analysis categories: publication date, country of origin, institutions involved and journal name. For the work authorship, the authors were classified according to the productivity in the field (number of articles published and the number of citations they had) and according to the productive framework: continuants, transients, newcomers, one-timers and terminators. Finally, from the analysis of the results, the trends for future researches in the field of knowledge in teacher professional development were identified.

From the trend analysis, it was observed that more than $60 \%$ of the articles were published in the last 5 years, which shows the rise of the theme. Regarding the country of origins of the publications, $49 \%$ concentrated between the United States and Australia. Regarding the institutions involved, the universities represented a large part of the publications. The main institutions were Nanyang Technological University (Singapore), Hong Kong Institute of Education (Hong Kong), University of Queensland (Australia), University of Cambridge (England) and Purdue University (the United States), which contributed with 14 to 27 publications each.

On the analysis of the most prolific journals, the highlights were Teaching and Teacher Education and International Journal of Science Education, containing 66 and 18 articles published respectively.

Regarding the analysis of the authorship of publications, $7.4 \%$ of the articles were written by newcomers, $0.3 \%$ by continuants, $4.3 \%$ by terminators and $88 \%$ by one-timers, which shows that only recently has the theme been included in the international academy scientific production.

The most productive author in terms of number of publications was Ian Hardy (11 articles), followed by Okhee Lee ( 7 articles), and they were classified as continuant and transient, respectively. Regarding the number of GCS citations, the most productive authors were Hilda Borko (157 citations), Lee Shulman (121 citations), Michael Garet (115 citations) and Laura Desimone (112 citations). Nevertheless, the most cited authors were, mostly, classified as terminators and, also, the majority of the publications took place from 1987 to 2004, not being 
classified as recent. From that information, it was inferred that the authors with the largest number of publications represent the main researchers in the field nowadays and that the most cited ones are researchers who, in most part, are either leaving the field or are not very active.

The largest production was of 11 papers by author and the most mentioned one had 157 citations. It was concluded that the thematic has been getting attention from the researchers of several fields of knowledge, including business, and that the authors inserted in the theme are seeking the consolidation of the theoretical basis regarding the subject by using empirical work.

Concerning the main publications mapped, it is observed that most of the articles are theoretical, which corroborates with the rise of the field in the last five years, and the recent recovery (since 2006) of the researches regarding the subject in questions. Thus, it is inferred that the authors engaged in this theme are seeking consolidation of theoretical basis concerning the subject, and through some empirical work, consolidating them. Therefore, this is the elaboration of the research theme approached.

Teacher professional development takes place through a non-linear process, therefore, the lack of consensus regarding how this process can be approached in programs of teacher training, as trends for future researches, the survey of experiences lived by teachers during their training is highlighted. Such experiences can point the difficulties faced by trial and error, and learnings which helped in their development and improvement of their practices in the classroom.

\section{References}

Andersson, C., \& Palm, T. (2017). The Impact of Formative Assessment on Student Achievement: A Study of the Effects of Changes to Classroom Practice after a Comprehensive Professional Development Programme. Learning and Instruction, 49, 92-102.

Avalos, B. (2011). Teacher Professional Development in Teaching and Teacher Education over Ten Years. Teaching and Teacher Education, 27, 10-20.

Clarke, D., \& Hollingsworth, H. (2002). Elaborating a Model of Teacher Professional Growth. Teaching and Teacher Education, 18, 947-967.

Clarke, D., \& Peter, A. (1993). Modelling Teacher Change. Proceedings of the Sixteenth Annual Conference of the Mathematics Education Research Group of Australasia (pp. 167-175). Brisbane: MERGA.

Day, C. (1999). Developing Teachers: The Challenges of Lifelong Learning. London: Falmer Press.

Day, C. (2001). Desenvolvimento Profissional de Professores: Os desafios da aprendizagem permanente. Portugal: Porto.

Desimone, L. M. (2009). Improving Impact Studies of Teachers' Professional Development: Toward Better Conceptualizations and Measures. Educational Researcher, 38, 181-199.

Fullan, M. (1982). The Meaning of Educational Change. New York: Teacher College Press.

Guarido Filho, E. R., Machado-Da-Silva, C. L., \& Gonçalves, S. A. (2009). Institucio- 
nalização da teoria institucional no contexto dos estudos organizacionais no Brasil. Proceedings of the XXXIII Encontro Nacional da ANPAD (pp. 1-16). São Paulo: Hotel Transamérica.

Guedes, V. L. S., \& Borschiver, S. (2005). Bibliometria: Uma ferramenta estatística para a gestão da informação e do conhecimento, em sistemas de informação, de comunicação e de avaliação científica e tecnológica. Proceedings of the CINFORM-Encontro Nacional de Ciência da Informação (pp. 1-18). Salvador.

Guskey, T., \& Sparks, D. (2002). Linking Professional Development to Improvements in Student Learning. In Proceedings of the Annual Meeting of the American Educational Research Association (pp. 1-7).

Hargreaves, A., \& Fullan, M. (1992). Understanding Teacher Development. New York, NY: Teachers College Press.

Heideman, C. (1990). Programming for Staff Development. New York, NY: Falmer Press.

Hollingsworth, H. (1999). Teacher Professional Growth: A Study of Primary Teachers Involved in Mathematics Professional Development. Theses. http://works.bepress.com/hilary_hollingsworth/15/

Kelchtermans, G. A. (1995). Utilização de biografias na formação de professores. Aprender, 18, 5-20.

Lather, P. (2005). Scientism and Scientificity in the Rage for Accountability: A Feminist Deconstruction. In Proceedings of the First International Congress of Qualitative Inquiry (pp. 1-19).

Marcelo, C. (2009). Desenvolvimento profissional docente: Passado e futuro. Sísifo: Revista de ciências da educação, 8, 7-22.

Miccoli, L. S. (1997). Learning English as a Foreign Language in Brazil: A Joint Investigation of Learners' Experiences in a University Classroom or Going to the Depth of Learners' Classroom Experiences. Doctoral Dissertation, Record No. NQ28294.

OECD Organisation for Economic Co-operation and Development (2005). Teachers Matter: Attracting, Developing and Retaining Effective Teachers. https://www.oecd.org/edu/school/34990905.pdf

Opfer, V. D., \& Pedder, D. (2011). Conceptualizing Teacher Professional Learning. Review of Education Research, 81, 376-407. https://doi.org/10.3102/0034654311413609

Rudduck, J. (1991). Innovation and Change. Modern Educational: Thought Series. Toronto: OISE Press.

Silva, D. A. L., Silva, E. J., \& Ometto, A. R. (2016). Green Manufacturing: Uma análise da produção científica e de tendências para o futuro. Production, 26, 642-655.

Thulasi, K., \& Arunachalam, S. (2010). Mapping of Cholera Research in India using HistCite. Annals of Library and Information Studies, 57, 310-326.

Villegas Reimers, E. (2003). Teacher Professional Development: An International Review of Literature. Paris: International Institute for Educational Planning.

Walter, S. A., \& Bach, T. M. (2013). Inserção de Pesquisadores Entrantes na Área de Estratégia: Análise das Relações de Autoria e Temas Estudados no Período de 1997-2010. REAd, 19, 165-191. https://doi.org/10.1590/S1413-23112013000100007 